\title{
How responsibility professional burnout inlay enforcement staff
}

\author{
G.A. Shurukhina ${ }^{1 *}, A . R$. Biktagirova ${ }^{2}$, and T.S. Chuykova ${ }^{3}$ \\ ${ }^{1}$ Bashkir State Pedagogical University named after M. Akmulla, Ufa, Russia \\ ${ }^{2}$ Bashkir State Pedagogical University named after M. Akmulla, Ufa, Russia \\ ${ }^{3}$ Bashkir State Pedagogical University named after M. Akmulla, Ufa, Russia
}

\begin{abstract}
The article presents the empirical study results of how responsibility effects professional burnout in law enforcement staff. The responsibility was studied in line with the systemic functional approach to the personality traits study by A.I. Krupnov with regard to eight components and sixteen variables. The study involved law enforcement staff who have service experience of up to five and more years. The findings allowed us to determine professional burnout reasons in staff with shorter service experience. They are influenced by responsibility variables characterized by personal motivation focus (self-centeredness), activity (energy), external control locus (externality) - Psychoemotional Exhaustion scale, avoiding responsible decisions (anergy) - Depersonalization scale, personally centered goals and personal difficulties (personally meaningful goals and personal difficulties) - Personal Achievements Reduction scale. The professional burnout of the staff with service experience of more than five years are influenced by responsibility variables such as energy and asteness (activity and negative emotions) - correlation with the Psychoemotional Exhaustion scale, subjectivity - with the Depersonalization scale, personally centered goals (personally meaningful goals), personal difficulties variable - with the Personal Achievements Reduction scale. The self-centeredness and externality (personally centered motivation and external control locus) variables show how responsibility effects professional burnout in shorter experienced staff. These variables affect psychoemotional exhaustion. Whereas the staff who have service experience of more than five years are emotionally exhausted by negative emotions increase (asteness)when implementing the responsibility. Based on the research findings, recommendations were made to prevent professional burnout and harmonize responsibility as a personality trait.
\end{abstract}

\section{A problem statement}

The law enforcement staff service experience is associated with a risk to life and health, numerous stressful situations and emotional upheavals. So, this requires high standards on the personality of a professional. High professional aspirations, an increased sense of social

${ }^{*}$ Corresponding author: ipcs-profped@yandex.ru 
justice, interpersonal dealings in a team, responsibility, workload, etc. are causes of professional burnout in law enforcement staff. On the one hand, these are an integral part of their activity, and on the other hand, these affect professional burnout. This contradiction is the study issue. It identifies how responsibility effects professional burnout in law enforcement staff who have service experience.

\subsection{The objective of the work}

The study issue is defined by understudied law enforcement staff responsibility professional peculiarities in line with the systemic functional approach. It is necessary to identify how responsibility and service experience effect professional burnout. Thus, we need to develop recommendations, intervention programs aimed at preventing professional burnout and harmonizing responsibility as a personality trait. The research is studied in line with the systemic functional approach. There responsibility is viewed as a system of stable contentsemantic and instrumental-stylistic characteristics that ensure the state of readiness and the desire of the subject to undertake and fulfill obligations.

The structural and functional approach concept by A.I. Krupnov includes all life aspects and various personality traits as a complex functioning system. It is based on the point of view on a personality as a multi-level and multidimensional system, where any personality trait is a complex systemic formation [1]. A.I. Krupnov considers personality traits, including responsibility, with regard to eight components and sixteen variables. It allows us to study any personality trait in a complex, multidimensional manner. Motivationalsemantic and instrumental-stylistic characteristics are shown in the each component polar qualities expression degree. There are setting-target (socially meaningful and personally meaningful goals), motivational (sociocentricity and self-centeredness), cognitive (meaningfulness and awareness), productive (objectivity and subjectivity), dynamic (energy and anergy), emotional (steness and asteness), regulatory (internality and externality) and reflexive-evaluative (operational and personal difficulties) [2].

In line with the systemic functional approach, the responsibility psychological structures was studied compared with the sociability and self-discipline of students - future managers [3], cadets of a military university [4], students with different control locus [5]. The responsibility factor structure was studied among junior and experienced lawyers [6], as well as in the context of the person social competence formation [7], as a systemic trait of the men personality in relation to the paternity phenomenon [8], as a professionally important personality [9], in alimentary fathers who pay and evade the payment of alimony [10], etc.

Professional burnout is the process of reducing or losing a person's experience of the significance of personal values. It characterized by difficulties in their implementation and inadequate emotional response in value-relevant situations [11, 12]. Foreign and Russian psychologists have identified various reasons for professional or emotional burnout. Personal characteristics that aggravate professional burnout include: character traits, personality traits accentuation, reflexivity level, etc. The professional burnout signs are emotional exhaustion (indifference, emotional satiety), depersonalization (negative attitude to one's professional activity or colleagues), reduction (subjective perception of oneself as a non-professional). Thus this staff category need the psychologist professional assistance $[13,14,15]$.

The burnout phenomenon occurs not only in the caring profession sphere, but also in other spheres of activities associated with a risk to life (military staff, law enforcement staff, penal system staff, etc.) [16, 17]. The law enforcement staff professional activities unique features require such a personal quality as responsibility. Along with a developed 
volition and activity self-control, the responsibility is the key to successful professional formation and self-development in law enforcement agencies [18].

For law enforcement staff, the development of professional burnout is provoked by work with great responsibility, psychological stress in a constant hard mode, personal interaction with special groups and stressful situations. It indicates a discrepancy between the desire of staff to have a high level of independence and to identify the methods and ways to achieve those results of service they are responsible for $[19,20]$.

\section{Materials and the results of the research}

The study purpose: to identify how responsibility effects professional burnout in law enforcement staff who have different service experience. Based on the research purpose, the following tasks were solved: to systematize and generalize the responsibility study in line with the systemic functional approach and professional burnout, to highlight how responsibility effects professional burnout based on correlation analysis, to develop practical recommendations for the professional burnout prevention. The study involved law enforcement staff with different service experience. It includes 32 people who have experience not exceeding 5 years, their average age is 29 years and 29 people who have experience of over 5 years, their average age is 33 years. 59 staff members are men and 2 are women. It corresponds to the law enforcement agencies activities specifics. To conduct an empirical study, we used the Blank Test - Responsibility by A.I. Krupnov and Professional burnout checklist by K. Maslach, S. Jackson, adapted by V.E. Vodopyanova. Spearman's rank correlation coefficient was used for the research results mathematical processing.

48 possible correlations were revealed of how responsibility effects professional burnout in law enforcement staff who have service experience of up to five years. We identify six significant connections. Three of them are negative (Fig. 1).

The self-centeredness $(\mathrm{r}=0,595)$ and externality $(\mathrm{r}=0,566)$ are positively and energy $(\mathrm{r}$ $=-0,42$ ) variables are negatively interconnected with the Psychoemotional Exhaustion scale. This means that staff have a reduced emotional state, indifference or emotional oversaturation, because their responsibility is more often motivated by the desire to assert themselves and feel in the eyes of others as a serious and obligatory person, a desire to test their capabilities (self-centeredness). The reason is that the more often they are inclined to believe that they would treat many cases more responsibly if they were asked more strictly for this, that the responsibility showing is often restrained by the fact that it is not always appreciated at its true worth (externality). They feel more negative about their service, when they more often perform tasks irresponsibly, are not always sure of their promises, and avoid joint tasks. Therefore,psychoemotional exhaustion often occurs with an increase in personal motivation and external control locus and an irresponsible attitude towards their professional duties.

The anergy dynamic component variable is positively associated with the Depersonalization scale $(r=0,601)$. The more often staff avoid situations where they need to undertake responsibility for themselves, they are obligatory only when others require it, the more their own "I" becomes alienated, the lack of emotional involvement with colleagues is experienced. In other words, when passivity is increasing in responsibility showing, the negative self-perception increases. 


\section{SOCIALLY SIGNIFICANT GOALS}

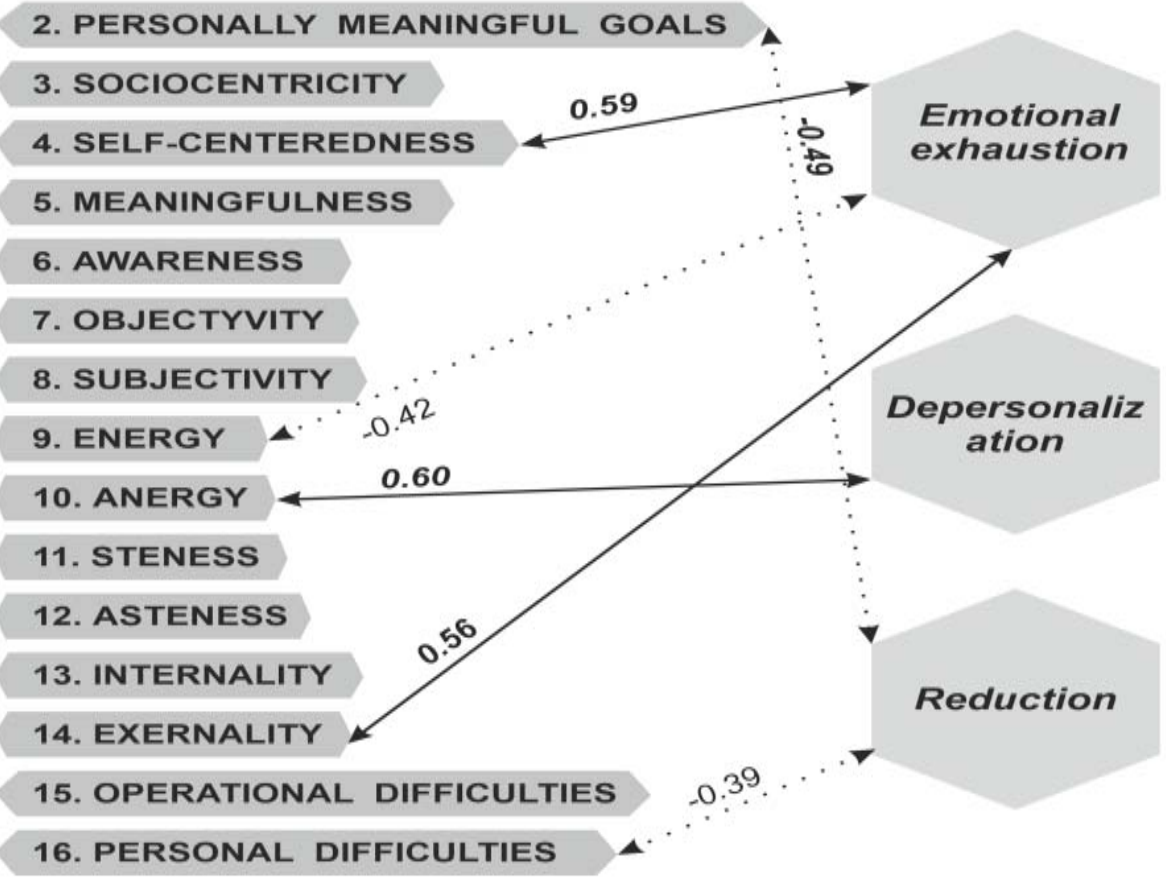

Fig. 1. Correlations coefficients of the responsibility variables and professional burnout indicators in law enforcement staff who have service experience of up to 5 years $(\mathrm{N}=32)$.

Negative correlations were revealed for the personal meaningful goals variable $(\mathrm{r}=$ $0,495)$ and personal difficulties variable $(\mathrm{r}=-0,39)$ with the Personal Achievements Reduction scale. This means that staff have negative self-esteem and professional devaluation, because their responsibility is less focused on fulfilling personal plans, improving themselves and their abilities, less often the desire to overcome uncertainty when implementing responsibility. That is, their negativism increases to their professional duties with a decrease in personal focus and desire for self-development when implementing responsibility.

48 possible correlations were revealed of how responsibility effects professional burnout in law enforcement staff who have service experience of over five years. We identify six significant connections. Three of them are negative (Fig. 2).

The Psychoemotional exhaustion scale is negatively correlated with the energy variable and positively correlated with the asteness variable $(\mathrm{r}=-0,623 ; \mathrm{r}=0,71$ respectively). This means that staff who have service experience of over 5 years have a reduced emotional state and less emotional oversaturation, because they more often carry out the task responsibly, even if it is not controlled, they always make a firm promise, because they are convinced that they will do it without fail (energy). At the same time, when they uncertainty performing important tasks their negative emotional state is aggravated by anger and irritation, if there is a failure in important matters (asteness). In other words, 
increasing activity in the responsibility manifestation reduces the negative state, and the growth of negative emotions increases emotional satiety.

The subjectivity $(\mathrm{r}=-0,580)$ and responsibility anergy $(\mathrm{r}=0,48)$ variables are correlate significantly with the Depersonalization scale. The subjectivityvariable negative value indicates that staff who have service experience of over five years show more destructions when interacting with other people, when their responsibility less often contributes to the development of self-confidence and their strengths, the acquisition of new self-control, selfregulation and volitional qualities development methods, when avoiding important tasks and not fulfilling promises (anergy). In other words. Decreased responsibility productivity, passivity and responsible tasks avoidance increases negativity towards other people.

The personally meaningful goals $(\mathrm{r}=-38)$, personal difficulties $(\mathrm{r}=-0,79)$ variables are negatively associated with the Personal Achievements Reduction scale. This means that their subjectivity of perceiving themselves as a non-professional is more, when they achieve less material well-being, personal plans fulfillment, uncertainty when implementing responsibility, and low self-esteem when performing important tasks. That is, subjectivity increases when the personal goals achievement and the personal difficulties solution when implementing responsibility decrease. So, this leads to their professional achievements devaluation. Based on the study results, the recommendations for the professional burnout prevention were made for psychologists working with law enforcement staff.

\section{SOCIALLY SIGNIFICANT GOALS}

\section{PERSONALLY MEANINGFUL GOALS}

\section{SOCIOCENTRICITY}

\section{SELF-CENTEREDNESS}

Emotional

5. MEANINGFULNESS

6. AWARENESS

7. OBJECTYVITY

8. SUBJECTIVITY

9. ENERGY

10. ANERGY

11. STENESS

12. ASTENESS

13. INTERNALITY

14. EXERNALITY

15. OPERATIONAL DIFFICULTIES

16. PERSONAL DIFFICULTIES

exhaustion

$\boldsymbol{\gamma}$
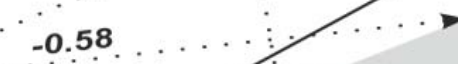
ation

Reduction

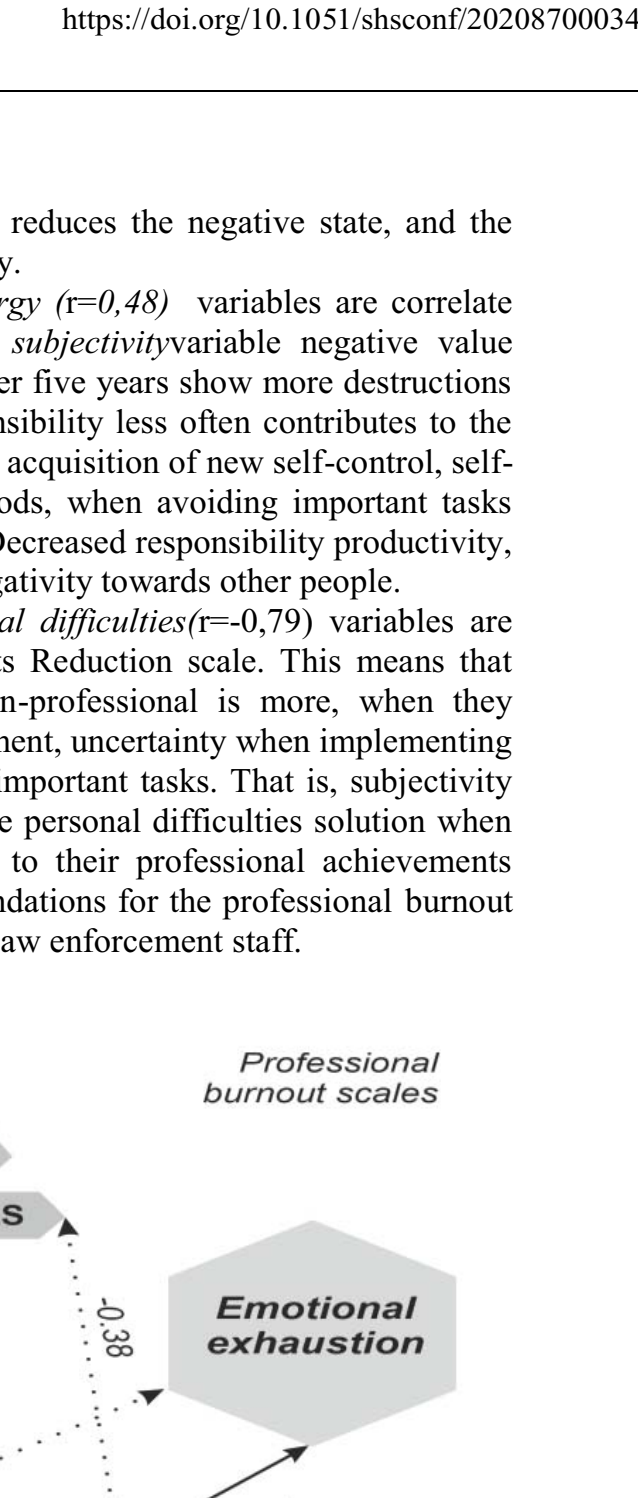

(1)

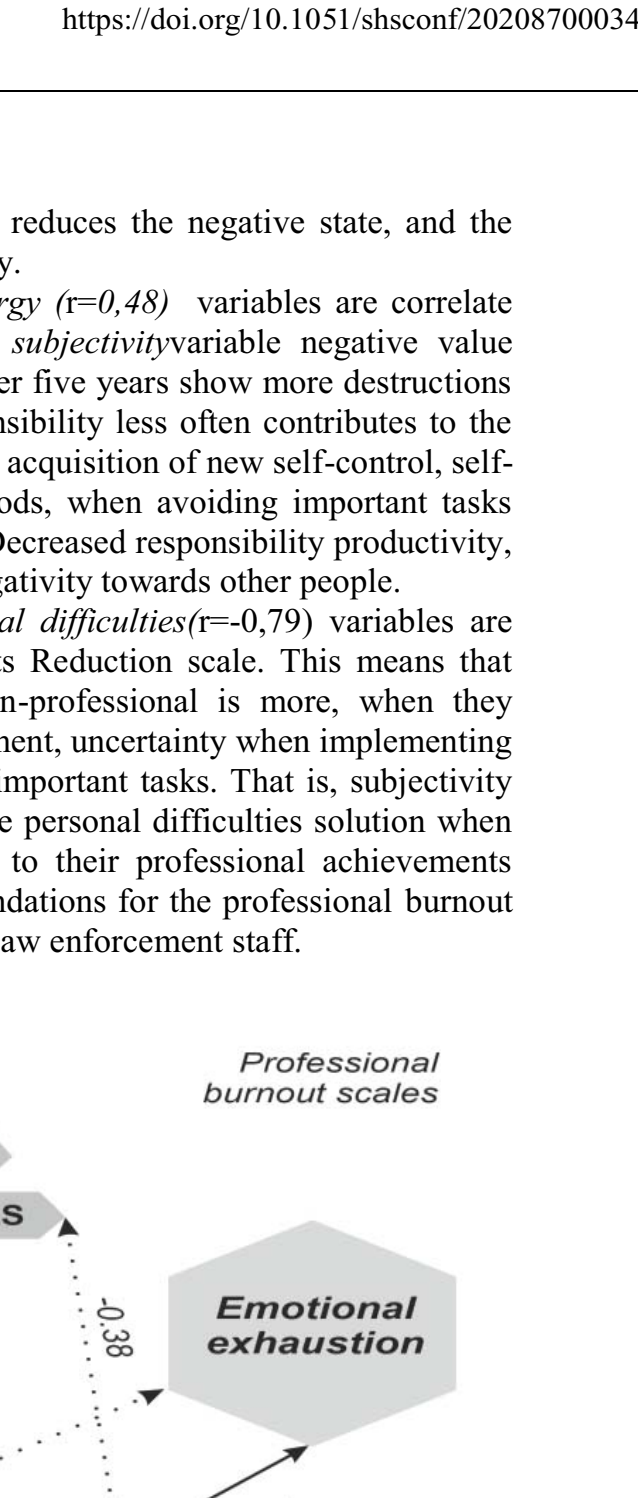

Depersonaliz

Fig. 2. Correlations coefficients of the responsibility variables and professional burnout indicators in law enforcement staff who have service experience of over 5 years $(\mathrm{N}=32)(\mathrm{N}=29)$. 


\section{Conclusions}

Thus, the responsibility and professional burnout in law enforcement staff who have service experience of up to five years iscorrelated in the following variables. There are selfcenteredness (personal motivational responsibility focus), energy (striving for responsible assignments with a negative value) and externality (external control locus when implementing responsibility, with the Psychoemotional scale; passivity or avoiding responsible decisions (anergy) variables. They are associated with a loss of interest in their professional service (Depersonalization scale). Personal responsibility focus (personally meaningful goals) and personal difficulties increase the subjectivity of perception of their professionalism (Personal Achievements Reduction scale).

The responsibility and professional burnout in law enforcement staff who have service experience of over five years is correlated in the following variables. There are energy and asteness variables with the Psychoemotional exhaustion scale, responsibility productivity (subjectivity) and changes in self-awareness (Depersonalization scale). There are also personal difficulties and its impact on devaluation of oneself as a professional (Personal Achievements Reduction scale).

The self-centeredness and externality (personally centered motivation and external control locus) variables show how responsibility effects professional burnout in shorter experienced staff. These variables affect psychoemotional exhaustion. Whereas the staff who have service experience of more than five years are emotionally burn out by negative emotions increase (asteness)when implementing the responsibility.

The direction for future research: to study how responsibility effects professional burnout in female law enforcement staff.

\section{References}

1. A.I. Krupnov, System-dispositional approach to the study of personality and its traits. Vestnik RUDN. Pedagogy and Psychology Series, 1, 63-74 (2006)

2. A.I. Krupnov, I.A. Novikova, History and conceptual foundations of the systemicfunctional approach to the personality traits study. Systemic studies of personality traits for the 30th anniversary of the Scientific School of A.I. Krupnov at RUDN: Collective Monograph, p. 9-30 (2014)

3. A.G. Aleikin, Comparative analysis of the characteristics and psychological structures of sociability, self-discipline and responsibility of students - future managers and specialists in the people management field, 5, 215-223 (2011)

4. T.M. Bespalova, The psychological structure specifics of the military members responsibility as a professionally important personality trait, 3, 107-111 (2012)

5. E.I. Karamova, G.A. Shurukhina, Systemic study of responsibility among students with different control locus. Modern Pedagogical Education Issues, 56 (3), 327- 335 (2017)

6. A.G. Perlin, Factor structure of personality responsibility among junior and experienced lawyers. Materials of the Interuniversity Scientific Conference, p. 25-26 (1999)

7. O.N. Mikhailova, The issue of responsibility within the personality social competence formation, 2 (26), 125-12 (2016)

8. M.V. Pastukhova, Responsibility as a personality trait within paternity psychology: some aspects. Relevant problems of psychology and pedagogy in the modern world: Materials of the International Research and Practical Conference, 228-232 (2013) 
9. N.A. Fomina, A.G. Aleikin, Sociability, self-discipline and responsibility as professionally important personality traits of manager students, 3 (22), 104-110. (2011)

10. G.A. Shurukhina, M.V. Nukhova, G.A. Mitina, Peculiarities of responsibility for alimony-liable fathers who pay and evade alimony. Modern Pedagogical Education Issues. Pedagogy and Psychology Series, 67 (3), 327-332 (2020)

11. S.A. Babanov, Professional factors and stress: burnout syndrome. Problem patient, 2 , 40-45 (2009)

12. M.V. Barabanova, M.V, Study of the psychological content of burnout syndrome, Vestnik Moskovskogo universiteta, 1, 54-59 (2013)

13. R. Rada, Jonson-Leong C. Stress, burnout, anxiety and depression among dentists. In: JADA, 135, 788-794 (2004)

14. E. Job Grunfeld, Stress and job satisfaction of cancer workers. Psychooncology, 14, 61-69 (2005)

15. V.E. Oryol, Burnout syndrome in foreign psychology: empirical research and prospects, 22 (1), 90-101 (2009)

16. V.E. Oryol, A.A. Rukavishnikov, The burnout phenomenon as the professional service impact on a person. M.: Prosveshchenie, p. 165 (2012)

17. L.Z. Gosteva, Social factors causing the occurrence of the professional burnout syndrome among employees of internal affairs. Psychological journal, 9, 23-26 (2010)

18. S.V. Tiunov, Prevention of burnout syndrome among specialists working in extreme conditions. Psychological Problems of the Family and the Personality in the Metropolis, p. 285-295 (2012)

19. O.E. Lisova, Psychological characteristics of the personality of MIA Russia employees performing various social and professional functions, 24, 960-965 (2011)

20. L.U. Nezhkina, I.V. Yaroslavtseva, Personal and business qualities of the Bodies of Internal Affairs. Vestnik of the St. Petersburg University of the Ministry of Internal Affairs of Russia, 3 (71), 200-205 (2016) 